\title{
A "Saga" of Adenanthera Pavonina Seed Ingestion in a Toddler
}

\section{Dear Editor,}

The adenanthera pavonina tree is commonly found in Southeast Asia, India and Southeast China. It has been introduced into some countries in the Americas (United States, Brazil, Costa Rica, Venezuela, Trinidad, Tobago, Cuba, Jamaica, and Puerto Rico). ${ }^{1,2}$ The trees are usually planted in many countries along roadsides, parks, and gardens to provide shade and as ornamental trees. The adenanthera pavonina seeds are seen inside curved hanging pods, which split open into two twisted halves to reveal the hard seeds. The seeds are glossy scarlet red (Fig. 1) and are commonly used as toys and ornaments. Children are attracted to these seeds due to the appealing look and use them as playthings. Often, toddlers might mistake these seeds for sweets and ingest them due to their attractive appearance.

The most adverse effects of this seed ingestion are limited to local gastrointestinal symptoms like vomiting and diarrhea. However, the majority of the

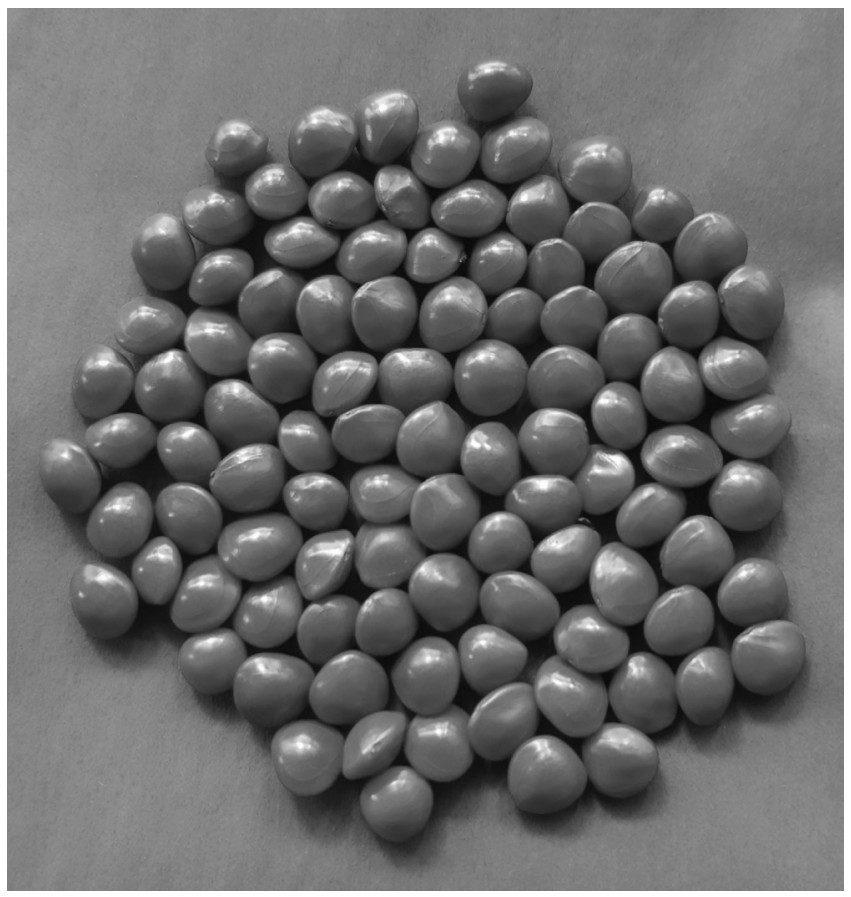

Fig. 1: Adenanthera pavonina seeds adenanthera pavonina seed ingestions often cause few or mild symptoms because the shell remains intact, and there is limited exposure to the toxic contents within the seed. We report a case of a child with the unintentional ingestion of raw adenanthera pavonina seeds resulting in gastrointestinal toxicity requiring hospitalisation. To our knowledge, this is the first paediatric case report on adenanthera pavonina toxicity.

\section{Case Report}

A 3 year-old boy who was previously well, presented to the paediatric emergency department (PED) with one episode of vomiting, which was non-bilious and non-projectile, and four episodes of non-bloody diarrhoea. There was also severe abdominal distention noted by the parents. The child had been playing with adenanthera pavonina seeds in front of the house. A few minutes after entering the house, the child suddenly had an episode of vomiting, the contents of which showed multiple scarlet red-colored fragments. Four hours after the ingestion, the child began complaining of intermittent abdominal pain lasting a few minutes during each episode, the intensity of which gradually worsened over time. Subsequently, the parents also noticed progressively worsening abdominal distention. There was no history of fever, lethargy, or decreased urine output, although the oral intake was reduced to less than half of the normal. There was also no history of contact with a person with symptoms of acute gastroenteritis or a significant travel history.

Upon arrival to the paediatric emergency department, he was awake, alert, and oriented, with initial vital signs at blood pressure of $91 / 59 \mathrm{mmHg}$, pulse of 103 beats/minute, respiratory rate of 22 breaths/ minute, and a temperature of $36.7^{\circ} \mathrm{C}$. Cardiac monitoring showed sinus tachycardia without ectopy or arrhythmias. On physical examination, his head, neck, heart, lung, and neurological exams were normal. The abdominal exam revealed gross distention, with generalised mild diffuse tenderness and hyperactive bowel sounds. The hernial orifices and 
external genitalia were normal. The rectal examination revealed no blood on the examining finger, and the anal tone was normal. The initial blood gas analysis was normal, and the electrocardiogram (ECG) showed normal sinus rhythm with a QTc $444 \mathrm{msec}$.

Laboratory tests revealed: sodium of $139 \mathrm{mEq} / \mathrm{L}$, potassium of $4.2 \mathrm{mEq} / \mathrm{L}$, chloride of $106 \mathrm{mEq} / \mathrm{L}$, bicarbonate of $20 \mathrm{mEq} / \mathrm{L}$, urea of $17 \mathrm{mg} / \mathrm{dL}$, creatinine of $0.27 \mathrm{mg} / \mathrm{dL}$ and glucose of $106 \mathrm{mg} / \mathrm{dL}$. Liver function tests, prothrombin time (PT), activated partial thromboplastin time (APTT), and complete blood counts were normal. Abdominal x-rays showed dilated small and large bowel loops till the descending colon with absent rectal gas (Fig. 2 and 3). Multiple air-fluid levels were also noted in the erect abdomen x-ray (Fig 2 and 3). There was no air under the diaphragm, and no radio-opaque foreign bodies were seen in the abdomen.

Intravenous access was secured, maintenance volume of intravenous fluid, and intravenous anti-emetic were administered. The patient was initially kept nil by mouth and was admitted for further monitoring. Upon re-evaluation in the inpatient ward, the patient persisted to have abdominal distension with diffuse tenderness, and the bowel sounds were sluggish on auscultation. He had intermittent episodes of diarrhoea, but vomiting had subsided. Over the next 72 hours, the abdominal distension and pain gradually resolved. Oral feeds were steadily escalated, and the patient was able

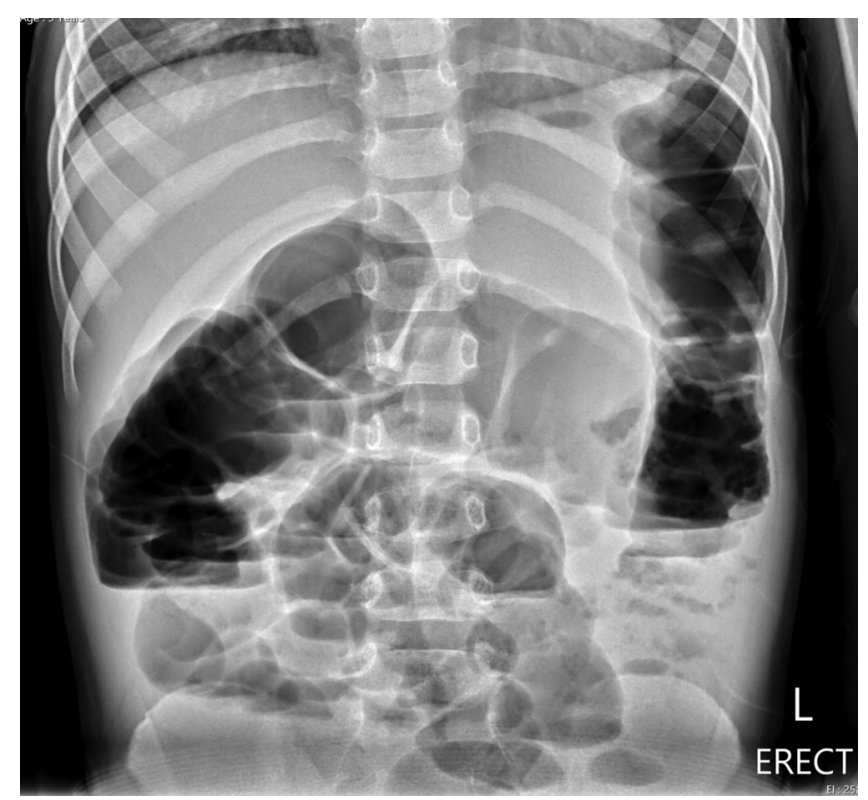

Fig. 2: X ray abdomen erect showing dilated small and large bowel loops with multiple air fluid levels and no air under the diaphragm or radio-opaque foreign bodies

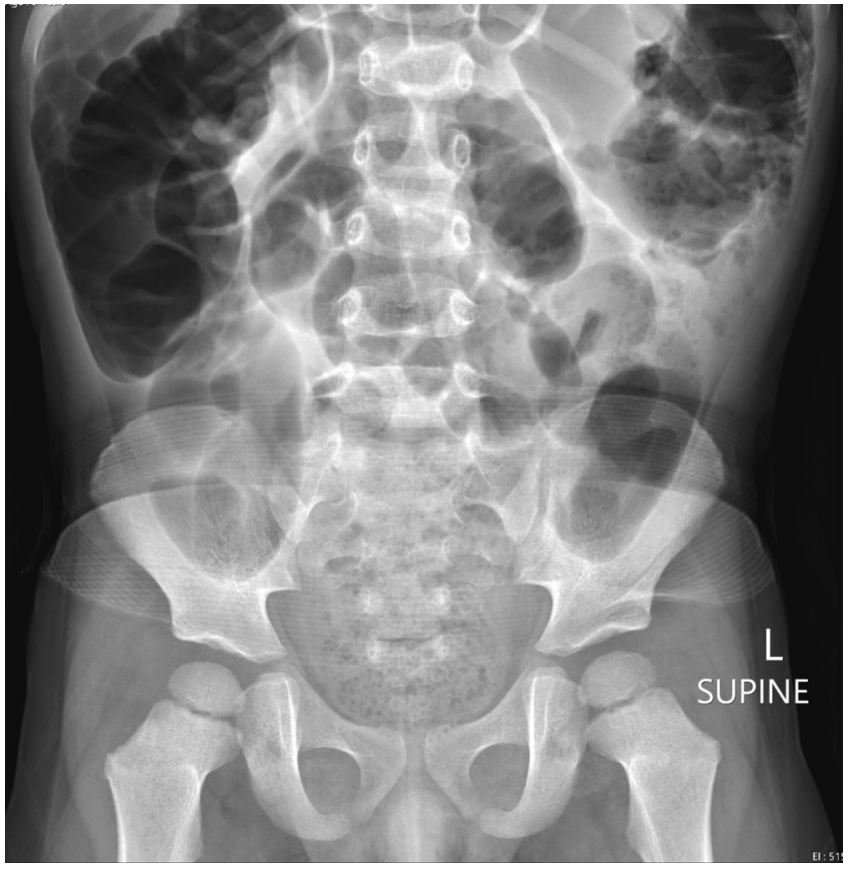

Fig. 3: X ray abdomen supine showing dilated small and large bowel loops till the descending colon with absent rectal gas

to achieve good oral intake. There were no further episodes of vomiting, diarrhoea, or abdominal discomfort. The patient was discharged home after 72 hours of inpatient monitoring. Two weeks follow up after the ingestion revealed no further sequelae from the ingestion.

\section{Discussion}

Adenanthera pavonina is an ornamental tree, which produces scarlet red, glossy seeds commonly used as toys and ornaments. While cooked adenanthera pavonina seeds are edible, the raw seeds are poisonous. These seeds are considered to possess medicinal value $^{3,4,6}$ and are used in traditional medicine. Powdered seeds are made into plastering pastes to quicken the removal of pus from the furuncle, cure headaches, and rheumatism. ${ }^{5}$ Adenanthera pavonina is a source of simple aromatic natural products like 2,4-dihydroxybenzoic acid, and flavonoids (ampelopsin, butein, dihydrorobinetin, androbinetin), as well as aliphatic natural products like O-acetylethanolamine and 1-octacosanol. ${ }^{2}$ It also contains carbohydrate (galactitol), terpenoids (echinocystic acid and oleanolic acid), steroids (daucosterol, $\beta$-sitosterol, and stigmasterol), amino acids and peptides (2-amino-4ethylidenepentanedioic acid and $\gamma$-methyleneglutamine), and alkaloids 
$(\mathrm{O}$-acetylethanolamine and $1 \mathrm{H}$-imidazole $) .^{2,6}$ The exact content within the seed which acts as the toxin is unknown, but the presence of aromatic and aliphatic natural products, flavonoids, terpenoids, natural steroids, amino acids, peptides, and alkaloids could act as gastrointestinal irritants. ${ }^{2,6}$

Due to the presence of the hard seed shell, which insulates the toxin from gastrointestinal absorption, oral ingestion of whole seeds usually does not produce serious illness. Symptomatic ingestions are more likely to happen after the consumption of new crops with immature seeds, which have a softer shell. In the case of older seeds, consumption, after chewing or grinding will disrupt the hard shell resulting in exposure of the gastrointestinal tract to the toxic contents of the seed. This mechanism likely increases the severity of toxicity and decreases the time to onset of symptoms.

The main symptoms from ingestion of these seeds are gastrointestinal in origin. These symptoms include nausea, vomiting, and diarrhoea, which, if untreated, can lead to severe dehydration. Significant abdominal distention due to toxic paralytic ileus, which happened in our paediatric patient, has not been previously reported in the literature. Severe toxicity can result in central nervous system stimulation and seizures. Adenanthera pavonina seed ingestion can also cause tachycardia, mydriasis, headache, hallucinations, weakness, and tremors. The plant may be irritating to the skin and the eye. ${ }^{7-9}$ Due to the irritative properties of the plant and seed contents, corrosive burns of oral mucosa and haematemesis may often be apparent within hours after ingestion. ${ }^{7-9}$ There is no known toxicity level in humans. Gastric emptying techniques, including induced emesis, activated charcoal, gastric lavage, and whole bowel irrigation, have not been found to be useful in this ingestion. However, in case of eye or skin exposure to the plant, copious irrigation has been recommended. There is no specific antidote for adenanthera pavonina seed poisoning. The treatment is mainly supportive with intravenous fluids, anti-emetics, and correction of electrolyte abnormalities. The stool and vomitus should not be discarded until the diagnosis is confirmed, as seed remnants may be present within these specimens.

\section{Summary}

The majority of cases of adenanthera pavonina seed poisoning in children involve the ingestion of a small number of intact seeds resulting in minimal or mild symptoms. However, the ingestion can be associated with significant gastrointestinal toxicity like toxic paralytic ileus, when the seeds are chewed. Intravenous fluids and supportive care in such cases will likely result in good outcomes. Emergency physicians should be aware of this toxic exposure and provide appropriate advice to parents.

\section{REFERENCES}

1. Lim TK. Adenanthera pavonina. In: Lim TK, editor. Edible Medicinal and Non-Medicinal Plants: Volume 2, Fruits. Dordrecht: Springer Netherlands; 2012. p. 506-12. Available at: https://doi.org/10.1007/978-94-007-1764-0_66. Accessed on 30 September 2019.

2. Adenanthera pavonina. In:Wikipedia.Available at: https://en.wikipedia. org/w/index.php?title=Adenanthera_pavonina\&oldid=915061992. Accessed on 29 September 2019.

3. Olajide OA, Echianu CA, Adedapo ADA, Makinde JM. Anti-inflammatory studies on adenanthera pavonina seed extract. Inflammopharmacology 2004;12:196-202.

4. Dholvitayakhun A, Cushnie TPT, Trachoo N. Antibacterial activity of three medicinal Thai plants against campylobacter jejuni and other foodborne pathogens. Nat Prod Res 2012; 26:356-63.

5. Tee SP. In : Wee ML, editor. Trees of Our Garden City: A Guide to the Common Trees of Singapore. 2nd ed. Singapore: National Parks Board, Singapore; 2001. p. 384

6. Silva IK, Soysa P. Evaluation of phytochemical composition and antioxidant capacity of a decoction containing adenanthera pavonina 1. and thespesia populnea 1. Pharmacogn Mag 2011; 7:193-9.

7. Jovanović M, Poljacki M, Duran V, Vujanović L, Sente R, Stojanović S. Contact allergy to compositae plants in patients with atopic dermatitis. Med Pregl 2004;57:209-18.

8. Reider N, Komericki P, Hausen BM, Fritsch P, Aberer W. The seamy side of natural medicines: contact sensitization to arnica (arnica montana 1.) and marigold (calendula officinalis 1.). Contact Dermatitis 200;45:269-72.

9. Zeller W, de Gols M, Hausen BM. The sensitizing capacity of Compositae plants. VI. Guinea pig sensitization experiments with ornamental plants and weeds using different methods. Arch Dermatol Res 1985;277:28-35.

Vigil James, ${ }^{1} M D$, Aswin Warier, ${ }^{2} M B B S, M D, M R C P C H$, Gene Yong Kwang Ong, ${ }^{1} M B B S, M R C P C H$

${ }^{1}$ Children's Emergency, KK Women's and Children's Hospital, Singapore ${ }^{2}$ Department of Emergency Medicine, Raffles Hospital, Singapore

Address for Correspondence: Dr Gene Ong Yong Kwang, Children's Emergency, KK Women's and Children's Hospital, 100 Bukit Timah Road, Singapore 229899

E-mail: geneong@yahoo.com 